\title{
Journal of Clinical and Surgical Pathology
}

Original Article

DOI: $10.36959 / 724 / 314$

\section{Craniopharyngiomas: A 20-Year-Period Evaluative Single Center Study}

Panche Zdravkovski, $M D^{1 *}$, Boro llievski, $M D^{1}$, Vesna Janevska, $M D, P h D^{1}$, Rubens Jovanovik, $M D, P h D^{1}$, Petar Cvetkovski, $M D^{2}$, Vladimir Rendevski, MD, PhD', Blagoj Shuntov, $M D^{3}$, Menka Lazareska, MD, PhD $D^{4}$, Milka Zdravkovska, MD, $P h D^{5}$ and Gordana Petrushevska, $M D, P h D^{1}$

\author{
${ }^{1}$ Medical Faculty, Institute of Pathology, University "Ss Cyril and Methodius", Skopje, Republic of North Macedonia \\ ${ }^{2}$ Private Health Institution "Biopsy", Skopje, Republic of North Macedonia \\ ${ }^{3}$ Public Health Institution - University Clinic for Neurosurgery, Skopje, Republic of North Macedonia \\ ${ }^{4}$ Public Health Institution - University Clinic for Radiology, Skopje, Republic of North Macedonia \\ ${ }^{5}$ University "Goce Delcev" - Štip, Republic of North Macedonia
}

\begin{abstract}
Introduction: Craniopharyngioma is a rare histologically benign brain tumor with potential malignant clinical course because of the high propensity of recurrence, deriving from the remnants of Ratkhe's pouch, presenting as solid mass and partly as fluid-filled cyst. There are two main histological subtypes: adamantinomatous and papillary. The aim of this study is to evaluate statistical features of this tumor in the Republic of North Macedonia.
\end{abstract}

Materials and Methods: This is a 20-year-period retrospective, single center evaluative study (1998-2018) of 40 craniopharyngioma cases operated in the University Clinic of Neurosurgery, diagnosed at the Institute of Pathology, Medical Faculty, University "Ss. Cyril and Methodius" in Skopje, Republic of North Macedonia on paraffin section slides routinely stained with H\&E. Statistica for Windows 7 was used.

Results: From total 4929 cases of benign and malignant brain tumors, craniopharyngioma comprise 40 cases $(0.81 \%) ; 25$ $(62.5 \%)$ males ( $37.9 \pm 17.8$ years), 15 (37.5\%) females ( $34.0 \pm 25.4$ years), age 3 to 68 years; Most prevalent localization: Sellar region - 11 (27.5\%), cerebrum - 8 (20\%). Adamantinomatous - 27 (67.5\%) cases, papillary 13 (32.5\%) cases. Age group distribution: the most cases - 7 (17.5\%) in 0-9, 40-49, 60-69 years groups; least cases - 3 (7.5\%) in 20-29 years group. Nine (22.5\%) of 40 patients have had recurrent tumor (first 1-3 years). Adamantinomatous was diagnosed in 14 (51.85\%) males and 13 (48.15\%) females; Papillary in 11 (84.62\%) males and 2 (15.38\%) females. There is significant statistical difference between age groups and craniopharyngioma subtypes (Kruskal-Wallis ANOVA: $H=14.86 ; p=0.0274$ ).

Conclusion: We found association/correlation between gender, age and histological subtype. Papillary craniopharyngioma appears more frequently in males and adamantinomatous was most prevalent in younger patients.

\section{Keywords}

Craniopharyngioma, Adamantinomatous, Papillary, Recurrence, Brain tumor, Benign

\section{Introduction}

Craniopharyngiomas are intracranial tumors that are typically both cystic and solid in structure. They occur most commonly in childhood and adolescence and, in later adult life, after the age of 50 years. They account for $2-4 \%$ of the primary brain tumors. Craniopharyngiomas are usually not discovered until they compress on important structures in their vicinity, and frequently present as quite large mass (over $3 \mathrm{~cm}$ ) when detected [1].
*Corresponding author: Panche Zdravkovski, MD, PhD Student, Institute of Pathology, Medical Faculty, University "Ss Cyril and Methodius", Skopje, Republic of North Macedonia, Tel: + 3897053-1595

Accepted: June 18, 2021

Published online: June 21, 2021

Citation: Zdravkovski P, llievski B, Janevska V, et al. (2021) Craniopharyngiomas: A 20-Year-Period Evaluative Single Center Study. J Clin Surg Pathol 3(1):16-20 
They are histologically benign tumors, but they tend to become adherent to structures in and around the pituitary gland and the pituitary stalk, including the optic nerves, optic chiasm, intracranial arteries and the brain itself. They are thought to arise from remnants of the craniopharyngeal duct or Rathke's pouch, which is a developmental structure related to the primitive gut. Embryonic cells from an incompletely involuted craniopharyngeal duct or anterior pituitary gland may give rise to a craniopharyngioma [2]. These tumors are closely related to another cystic mass, occasionally seen in the pituitary region, called Rathke's cleft cyst.

Craniopharyngiomas have two clinicopathological variants (adamantinomatous and papillary) that have distinct phenotypes and characteristic mutations. Adamantinomatous craniopharyngiomas show CTNNB1 mutations and aberrant nuclear expression of beta-catenin in as many as $95 \%$ of cases [3]. Papillary craniopharyngiomas show BRAF V600E mutations in $81-95 \%$ of cases, which can be detected by immunohistochemistry [4]. Craniopharyngiomas may be infiltrative and, therefore, clinically difficult to manage. Adamantinomatous craniopharyngioma has a bimodal age distribution, with incidence peaks in children aged 5-15 years and adults aged 45-60 years. Rare neonatal and fetal cases have been reported. Papillary craniopharyngiomas occur almost exclusively in adults, at a mean patient age of 40-55 years [5]. Craniopharyngiomas show no obvious gender predilection. The most common site for both subtypes is the suprasellar cistern, with a minor intrasellar component [6]. Unusual locations such as the sphenoid sinus and cerebellopontine angle have also been reported. Craniopharyngiomas, mainly the papillary variant, are also found in the third ventricle. The prognosis for each patient depends on several factors, including the ability of the tumor to be completely removed and the neurological deficits and hormonal imbalances caused by the tumor and the treatment $[7,8]$. Most of the problems with hormones and vision do not improve with treatment, and sometimes the surgery can make them even worse, because it may damage the brain structures neighboring the tumor.

Craniopharyngiomas have a high propensity for recurrence, mostly in the first 3 years after surgery. Overall recurrence rates range from $0-17 \%$ after total removal of the tumor and from $25-63 \%$ after partial removal of the tumor with radiotherapy [9].

\section{Materials and Methods}

This is a 20-year-period retrospective evaluative single center study (1998-2018) of 40 craniopharyngioma cases operated in the University Clinic of Neurosurgery, diagnosed at the Institute of Pathology, Medical Faculty, University "Ss. Cyril and Methodius" in Skopje, Republic of North Macedonia on paraffin section slides routinely stained with H\&E. Statistica for Windows 7 was used.

H\&E staining: Three-micron paraffin sections were made, then deparaffinized and rehydrated to tap water.

Later, the slides were stained with Gill III - Hematoxylin $3 x$ per 1 minute, then washed with tap water until blue dye stops coming off the slides. Decolorization is achieved by 1-minute dip in $0.5 \%$ acid alcohol and again wash in tap water. We proceed by adding a counterstain aqueous Eosin for 2 minutes, then dehydrate through 2 changes of $96 \%$ Ethanol and 3 changes of $100 \%$ Ethanol, 1 minute each change. We then clear in 3 changes of Neo-Clear - 1 minute each change and finish with mount and coverslip.

\section{Results}

From total 4929 cases of benign and malignant brain tumors, craniopharyngioma comprise 40 cases $(0.81 \%)$ (Figure 1); 25 (62.5\%) males (37.9 \pm 17.8 years), 15 (37.5\%) females ( $34.0 \pm 25.4$ years) (Figure 2), age 3 to 68 years; Most prevalent localization: Sellar region - $11(27.5 \%)$, cerebrum $8(20 \%)$. Adamantinomatous - 27 (67.5\%) cases, papillary 13 (32.5\%) cases (Figure 3). Age group distribution: the most cases - $7(17.5 \%)$ in 0-9, 40-49, 60-69 years groups; Least cases - 3 (7.5\%) in 20-29 years group. Nine (22.5\%) of 40 patients have had recurrent tumor (first 1-3 years). Adamantinomatous was diagnosed in 14 (51.85\%) males and 13 (48.15\%) females (Figure 4); Papillary in 11 (84.62\%) males and 2 (15.38\%) females (Figure 5). There is significant statistical difference between age groups and craniopharyngioma subtypes (Kruskal-Wallis ANOVA: $\mathrm{H}=14.86 ; \mathrm{p}=0.0274$ ).

During the examined period, the prevalence rate of diagnosed craniopharyngiomas was 0.10 per 100000 inhabitants. Most, 5 (12.5\%) cases were registered in 1999, with an incidence rate of 0.25 per 100000 inhabitants in that year (Table 1).

Table 1: Number of cases diagnosed annually/highest rate diagnosed in the 20 years period.

\begin{tabular}{|c|c|c|c|}
\hline Year & $\begin{array}{c}\text { Number of } \\
\text { Cases }\end{array}$ & $\mathbf{\%}$ & $\begin{array}{c}\text { Incidence Rate } \\
\text { per 100,000 } \\
\text { Inhabitants }\end{array}$ \\
\hline $\mathbf{1 9 9 8}$ & 3 & 7.5 & 0.15 \\
\hline $\mathbf{1 9 9 9}$ & 5 & 12.5 & 0.25 \\
\hline $\mathbf{2 0 0 0}$ & 1 & 2.5 & 0.05 \\
\hline $\mathbf{2 0 0 1}$ & 2 & 5.0 & 0.10 \\
\hline $\mathbf{2 0 0 2}$ & 3 & 7.5 & 0.15 \\
\hline $\mathbf{2 0 0 3}$ & 2 & 5.0 & 0.10 \\
\hline $\mathbf{2 0 0 4}$ & 2 & 5.0 & 0.10 \\
\hline $\mathbf{2 0 0 5}$ & 2 & 5.0 & 0.10 \\
\hline $\mathbf{2 0 0 6}$ & 2 & 5.0 & 0.10 \\
\hline $\mathbf{2 0 0 7}$ & 2 & 5.0 & 0.10 \\
\hline $\mathbf{2 0 0 8}$ & 2 & 5.0 & 0.10 \\
\hline $\mathbf{2 0 0 9}$ & 3 & 7.5 & 0.15 \\
\hline $\mathbf{2 0 1 0}$ & 1 & 2.5 & 0.05 \\
\hline $\mathbf{2 0 1 1}$ & 2 & 5.0 & 0.10 \\
\hline $\mathbf{2 0 1 2}$ & 1 & 2.5 & 0.05 \\
\hline $\mathbf{2 0 1 3}$ & 2 & 5.0 & 0.10 \\
\hline $\mathbf{2 0 1 4}$ & 2 & 5.0 & 0.10 \\
\hline $\mathbf{2 0 1 5}$ & 1 & 2.5 & 0.05 \\
\hline $\mathbf{2 0 1 6}$ & 1 & 2.5 & 0.05 \\
\hline $\mathbf{2 0 1 7}$ & 1 & 2.5 & 0.05 \\
\hline $\mathbf{2 0 1 8}$ & 0 & 0 & 0 \\
\hline & & & Prevalence \\
\hline Total & 40 & $100 \%$ & $0.10 / 100,000$ \\
inhabitants \\
\hline
\end{tabular}


Citation: Zdravkovski P, Ilievski B, Janevska V, et al. (2021) Craniopharyngiomas: A 20-Year-Period Evaluative Single Center Study. J Clin Surg Pathol 3(1):16-20

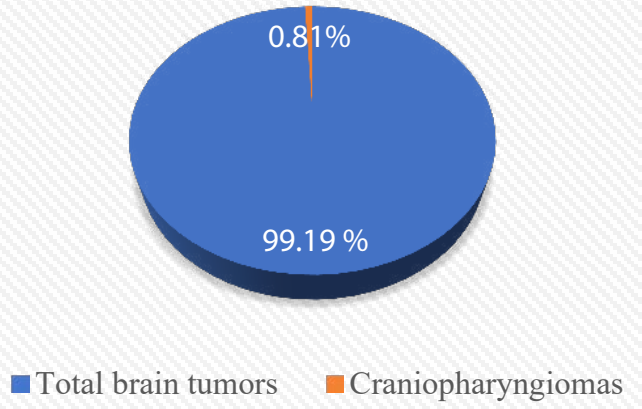

Figure 1: From total 4929 cases of benign and malignant brain tumors diagnosed in the 20-year period, craniopharyngioma comprise 40 cases $(0.81 \%)$.

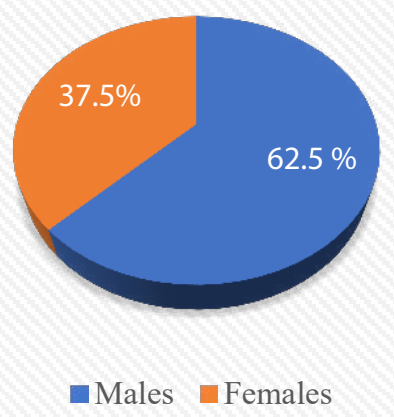

Figure 2: Twenty-five (62.5\%) of the craniopharyingioma cases were males with mean age of $37.9 \pm 17.8$ years, fifteen $(37.5 \%)$ of the craniopharyngioma cases were females with mean age of $34.0 \pm 25.4$ years.

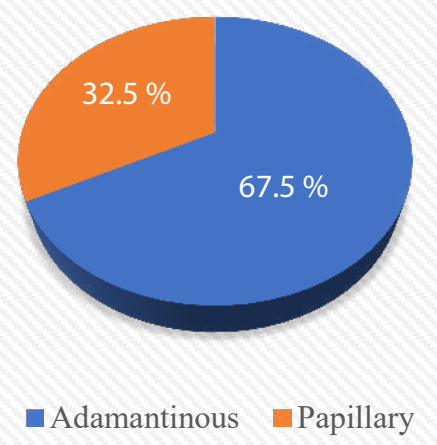

Figure 3: Adamantinomatous craniopharyngioma was diagnosed in 27 cases (67.5\%) and papillary craniopharyngioma was diagnosed in 13 cases (32.5\%).
Adamantinomatous subtype in both gender

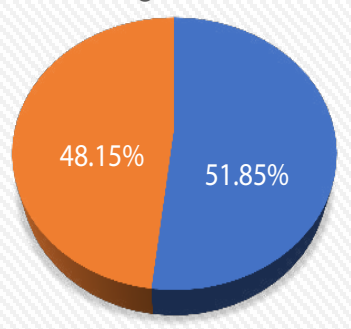

Males Females

Figure 4: Adamantinomatous craniopharyngioma in both gender was diagnosed in 14 males $(51.85 \%)$ and 13 females (48.15\%).

\section{Papillary subtype in both gender}

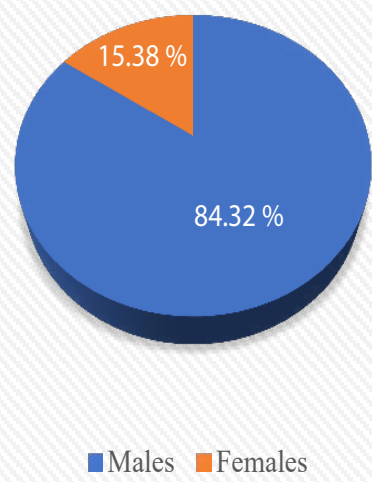

Figure 5: Papillary craniopharyngioma in both gender was diagnosed in 11 males (84.62\%) and 2 females (15.38\%).

The average age of patients was $36.4 \pm 20.7$ years, with the youngest patient being 3 years old and the oldest 68 years (Table 2). The average age of men was $37.9 \pm 17.8$ years, and for women $34.0 \pm 25.4$ years. There is no significant difference in age between men and women with diagnosed craniopharyngioma (Mann-Whitney U test: $Z=0.489 p=0.6246$ ). The highest number of patients -7 (17.5\%) belonged to the age groups from 0 to 9,40 to 49 , and 60 to 69 years, and the smallest number $-3(7.5 \%)$ were at the age of 20 up to 29 years.

Adamantinomatous craniopharyngioma was diagnosed in 14 (51.85\%) men and 13 (48.15\%) women, and papillary craniopharyngioma in 11 (84.62\%) men and in 2 (15.38\%) female patients (Table 3). There is an association/ correlation between the patient's gender and the type of craniopharyngioma (Fisher exact test: $p=0.0458$ ). Papillary craniopharyngiomas are significantly more common in men.

There is a statistically significant difference between age groups in relation to the type of craniopharyngiomas (Kruskal- 
Citation: Zdravkovski P, Ilievski B, Janevska V, et al. (2021) Craniopharyngiomas: A 20-Year-Period Evaluative Single Center Study. J Clin Surg Pathol 3(1):16-20

Table 2: Distribution of patients by age groups.

\begin{tabular}{|c|c|c|}
\hline Age Groups/Years & Number of Patients & \% \\
\hline $\mathbf{0 - 9}$ & 7 & 17.5 \\
\hline $\mathbf{1 0}-\mathbf{1 9}$ & 4 & 10.0 \\
\hline $\mathbf{2 0}-\mathbf{2 9}$ & 3 & 7.5 \\
\hline $\mathbf{3 0}-\mathbf{3 9}$ & 6 & 15.0 \\
\hline $\mathbf{4 0 - 4 9}$ & 7 & 17.5 \\
\hline $\mathbf{5 0}-\mathbf{5 9}$ & 6 & 15.0 \\
\hline $\mathbf{6 0}-\mathbf{6 9}$ & 7 & 17.5 \\
\hline Total & 40 & $100 \%$ \\
\hline
\end{tabular}

Table 3: Distribution of patients according to the histological type of craniopharyngioma and gender.

\begin{tabular}{|l|c|c|c|}
\hline Histological Type & Male & Female & Total \\
\hline \multirow{2}{*}{ Adamantinomatous } & 14 & 13 & 27 \\
\cline { 2 - 4 } & $51.85 \%$ & $48.15 \%$ & 27 \\
\hline \multirow{2}{*}{ Papillary } & 11 & 2 & 13 \\
\hline Total & $84.62 \%$ & $15.38 \%$ & 40 \\
\hline
\end{tabular}

Table 4: Distribution of patients under the histological type of craniopharyngioma and age groups.

\begin{tabular}{|c|c|c|c|}
\hline Age Groups & $\begin{array}{c}\text { Adamantinomatous } \\
\text { Craniopharyngioma }\end{array}$ & $\begin{array}{c}\text { Papillary } \\
\text { Craniopharyngioma }\end{array}$ & Total \\
\hline $\mathbf{0}-\mathbf{9}$ & $\mathbf{7}$ & 0 & 7 \\
\hline $\mathbf{1 0}-\mathbf{1 9}$ & 4 & 0 & 4 \\
\hline $\mathbf{2 0}-\mathbf{2 9}$ & 1 & 2 & 3 \\
\hline $\mathbf{3 0}-\mathbf{3 9}$ & 5 & 1 & 6 \\
\hline $\mathbf{4 0}-\mathbf{4 9}$ & 3 & 4 & 7 \\
\hline $\mathbf{5 0}-\mathbf{5 9}$ & 3 & 3 & 6 \\
\hline $\mathbf{6 0}-\mathbf{6 9}$ & 4 & 3 & 7 \\
\hline Total & 27 & 13 & 40 \\
\hline
\end{tabular}

Table 5: Distribution of patients by tumor localization.

\begin{tabular}{|l|c|c|}
\hline Localization & Number of Patients & $\%$ \\
\hline Sellar region & 11 & 27.5 \\
\hline Third ventricle & 6 & 15.0 \\
\hline Suprasellar and retrosellar region & 3 & 7.5 \\
\hline Sellar and suprasellar region & 4 & 10.0 \\
\hline Cerebrum & 8 & 20.0 \\
\hline Suprasellar and third ventricle & 1 & 2.5 \\
\hline Suprasellar region & 6 & 15.0 \\
\hline Cerebrum and supsrasellar & 1 & 2.5 \\
\hline Total & 40 & $100 \%$ \\
\hline
\end{tabular}

Wallis ANOVA: $\mathrm{H}=14.86 \mathrm{p}=0.0274)$. Adamantinomatous craniopharyngioma is significantly more pronounced in young people - aged 0 to 19 years (Table 4).

In most patients, the localization of craniopharyngioma was in Sellar region - 11 (27.5\%) and Cerebrum - 8 (20\%) (Table 5).

\section{Discussion}

In the period of 20 years (from 1998 to 2018), 40 cases of craniopharyngiomas were diagnosed in the Republic of North Macedonia, which is $0.81 \%$ of the total (4929) of diagnosed benign and malignant tumors in the investigated period. During the examined period, the prevalence rate of diagnosed craniopharyngiomas was 0.10 per 100000 inhabitants. Most, 5 (12.5\%) cases were registered in 1999, with an incidence rate of 0.25 per 100000 inhabitants in that year. Of the total of 40 patients, 25 (62.5\%) were men and 15 (37.5\%) of females.

The average age of patients was $36.4 \pm 20.7$ years, with the youngest patient being 3 years old and the oldest 68 years. The average age of men was $37.9 \pm 17.8$ years, and for women $34.0 \pm 25.4$ years. There is no significant difference in age between men and women with diagnosed craniopharyngioma (Mann-Whitney $U$ test: $Z=0.489 p=0.6246)$. The highest number of patients -7 (17.5\%) belonged to the age groups from 0 to 9,40 to 49 , and 60 to 69 years, and the smallest number -3 (7.5\%) were at the age of 20 up to 29 years.

Adamantinomatous craniopharyngioma was diagnosed in $27(67.5 \%)$ individuals, and papillary craniopharyngioma in 13 (32.5\%) patients. Adamantinomatous craniopharyngioma was diagnosed in 14 (51.85\%) men and 13 (48.15\%) women, and papillary craniopharyngioma in 11 (84.62\%) men and in $2(15.38 \%)$ female patients. There is an association/ correlation between the patient's gender and the type of craniopharyngioma (Fisher exact test: $p=0.0458$ ). Papillary craniopharyngiomas are significantly more common in men.

There is statistically significant difference between age groups in relation to the type of craniopharyngiomas (KruskalWallis ANOVA: $\mathrm{H}=4.86 \mathrm{p}=0.0274$ ). Adamantinomatous craniopharyngioma is significantly more pronounced in young people - aged 0 to 19 years. In most patients, the localization of craniopharyngioma was in Sellar region - 11 (27.5\%) and Cerebrum - $8(20 \%)$. Of the total of 40 patients with craniopharyngioma diagnosed during the study, 9 (22.5\%) experienced relapse of the tumor for a period of 1 to 3 years. (at the earliest the same year, and at the latest after 3 years).

Of the total of 40 patients with craniopharyngioma diagnosed during the study, 9 (22.5\%) experienced relapse of the tumor for a period of 1 to 3 years (at the earliest the same year, and at the latest after 3 years).

- In 6 of the patients, there was 1 recurrent tumor.

- In 1 patient, there were 2 recurrent tumors.

- In 2 patients, there were 3 recurrent tumors.

\section{Conclusion}

We found association/correlation between gender, age and histological subtype. Papillary craniopharyngioma appears more frequently in males and adamantinomatous was most prevalent in younger patients.

\section{References}

1. Lithgow K (2019) Craniopharyngiomas. Endotext.

2. Larkin S J, Ansorge O (2013) Pathology and pathogenesis of craniopharyngiomas. Pituitary 16: 9-17.

3. Martinez-Barbera JP, Buslei R (2015) Adamantinomatous craniopharyngioma pathology, molecular genetics and mouse models. J Pediatr Endocrinol Metab 28: 7-17. 
4. Bratianos PK, Taylor-Weiner A, Manley PE, et al. (2014) Exome sequencing identifies BRAF mutations in papillary craniopharyngioma. Nat Genet 46: 161-165.

5. Müller HL, Merchant TE, Warmuth-Metz M, et al. (2019) Craniopharyngioma. Nat Rev Dis Primers 5: 75.

6. Ortiz Torres M, Shafiq I, Mesfin FZ (2021) Craniopharyngioma. In: StatPearls [Internet]. StatPearls Publishing, Treasure Island (FL).
7. Lo AC, Howard AF, Nichol A, et al. (2014) Long-term outcomes and complications in patients with craniopharyngioma: the British Columbia Cancer Agency experience. Int J Radiat Oncol Biol Phys 88: 1011-1018.

8. Wijnen M, van den Heuvel-Eibrink MM, Janssen J, et al. (2017) Very long-term sequelae of craniopharyngioma. Eur J Endocrinol 176: 755-767.

9. Weiner HL, Wisoff JH, Rosenberg ME et al. (1994) Craniopharyngiomas: A clinicopathological analysis of factors predictive of recurrence and functional outcome. Neurosurgery 35: 1001-1010. 